\title{
Ecosystem Responses in the Distribution of Black Clam (Villorita cyprinoides) Beds in Vembanad Estuary during Environmental Changes Using GIS and RS
}

\author{
Thankam Theresa Paul'1, Grinson George², A. Dennis², N. R. Athira3 ${ }^{3}$, R. S. Biradar ${ }^{4}$, \\ Rajani Khandagale ${ }^{4}$, K. G. Padmakumar ${ }^{5}$ \\ ${ }^{1}$ Kochi Unit of Central Inland Fisheries Research Institute, Ernakulam North, India \\ ${ }^{2}$ Fishery Resources Assessment Division, Ernakulam North, India \\ ${ }^{3}$ Socio Economic Evaluation and Technology Transfer Division, Central Marine Fisheries Research Institute, Ernakulam North, \\ India \\ ${ }^{4}$ Socio Economic Evaluation and Technology Transfer Division, Central Institute of Fisheries Education, Versova, India \\ ${ }^{5}$ Former Associate Director of Research, Regional Agriculture Research Station, Kumarakom, India \\ Email: thankamtheresa@gmail.com, grinsongeorge@gmail.com,dennis_oceantech@gmail.com, athira31@gmail.com, \\ rsbiradar@gmail.com, rajani@gmail.com,kgpadman@gmail.com
}

How to cite this paper: Paul, T.T., George, G., Dennis, A., Athira, N.R., Biradar, R.S., Khandagale, R. and Padmakumar, K.G. (2017) Ecosystem Responses in the Distribution of Black Clam (Villorita cyprinoides) Beds in Vembanad Estuary during Environmental Changes Using GIS and RS. Journal of Geographic Information System, 9, 245-266.

https://doi.org/10.4236/jgis.2017.93015

Received: January 19, 2017

Accepted: May 15, 2017

Published: May 18, 2017

Copyright (c) 2017 by authors and Scientific Research Publishing Inc. This work is licensed under the Creative Commons Attribution International License (CC BY 4.0).

http://creativecommons.org/licenses/by/4.0/

\begin{abstract}
The biomass and distribution of black clam (Villorita cyprinoides) in Vembanad, a tropical estuary located along the southwest coast of India varied significantly. Sampling was done in freshwater-dominated zone in the south (distal) and brackish water zone in the north (proximal), during pre and post monsoon seasons. Clam biomass was estimated from samples, collected from different stations during the study period. Water transparency and temperature were measured at the sample sites. Water samples were collected and analysed for salinity, dissolved oxygen (DO), $\mathrm{pH}$ and hardness. There was a significant difference in the clam biomass during the two seasons in the distal zone, and those collected from the distal and proximal zones during premonsoon season. The data were further analysed to determine the factors affecting the clam biomass distribution in the two zones and seasons. Factor analyses, comparing the distal zone during two seasons and zonal variations were similar to earlier observations. Step wise regression analyses found that dissolved oxygen (adjusted $\mathrm{R}^{2}=0.3$ ) is the only variable affecting clam survival during pre-monsoon period in the distal and proximal zones. A geographic map of the region obtained from the Indian satellite sensor LISS (Linear Image Self Scanner) was used along with in situ data to map the results using inverse distance weightage model.
\end{abstract}




\section{Keywords}

Clam Beds, Inverse Distance Weightage, GIS, Monitoring, Environment, Model

\section{Introduction}

Tropical estuaries are highly productive and critical to the maintenance of coastal fisheries [1]. The faunal composition of such estuaries varies at spatial and temporal scales in response to the localised natural and human disturbances of different magnitudes [2] [3] [4]. There are observed seasonal variations in clam biomass across a tropical estuary and dredging inside the estuary can affect the spatial distribution.

Villorita cyprinoides which is a major molluscan resource of Vembanad estuary contribute $97 \%$ of the molluscan catches from India [5]. Clams are important for their nutritional benefits, and valued for their taste [6] [7]. But our limited knowledge on the spatial and temporal distribution of this invertebrate fauna restricts a better insight into the factors influencing their changes in community structure [8] [9] [10] which is essential for the better management of such species.

The distribution of clams in the Vembanad estuary is patchy. But being sedentary organisms, their survival and growth are dictated by a combination of favourable hydrographical conditions. The observations on environmental variables and their relation on clam biomass distribution in this study would help the fishing community to identify easily the zones of high abundance of the clams, in various geographic areas across the estuary and during the two seasons studied in the estuary.

\section{Methodology}

\subsection{Study Area}

Vembanad estuary, situated in Kerala, is the largest tropical wetland ecosystem along the south-west coast of India. This tropical estuary, fed by ten rivers draining into the Arabian Sea, covers an area of 21,050 ha spread between latitudes $9.59^{\circ} \mathrm{N}$ and $10.61^{\circ} \mathrm{N}$ and longitudes $76.19^{\circ} \mathrm{E}$ and $76.43^{\circ} \mathrm{E}$. The rich biodiversity of shell fish and other aquatic resources and their socio-economic importance, made Vembanad estuary a wetland of international importance, and is designated a "Ramsar site". A unique characteristic of the estuary is the Thaneermukkom salt water barrier which divides the water body into two zones-one with freshwater fed by the rivers on the southern side, and the other with brackish water fed both by rivers and Arabian Sea on the northern side (Figure 1). Our study was conducted in these two zones in Vembanad estuary where the freshwater zone is termed as distal and the brackish zone as proximal. The zonation is relative to the mouth of the lake. The sampling was done during 


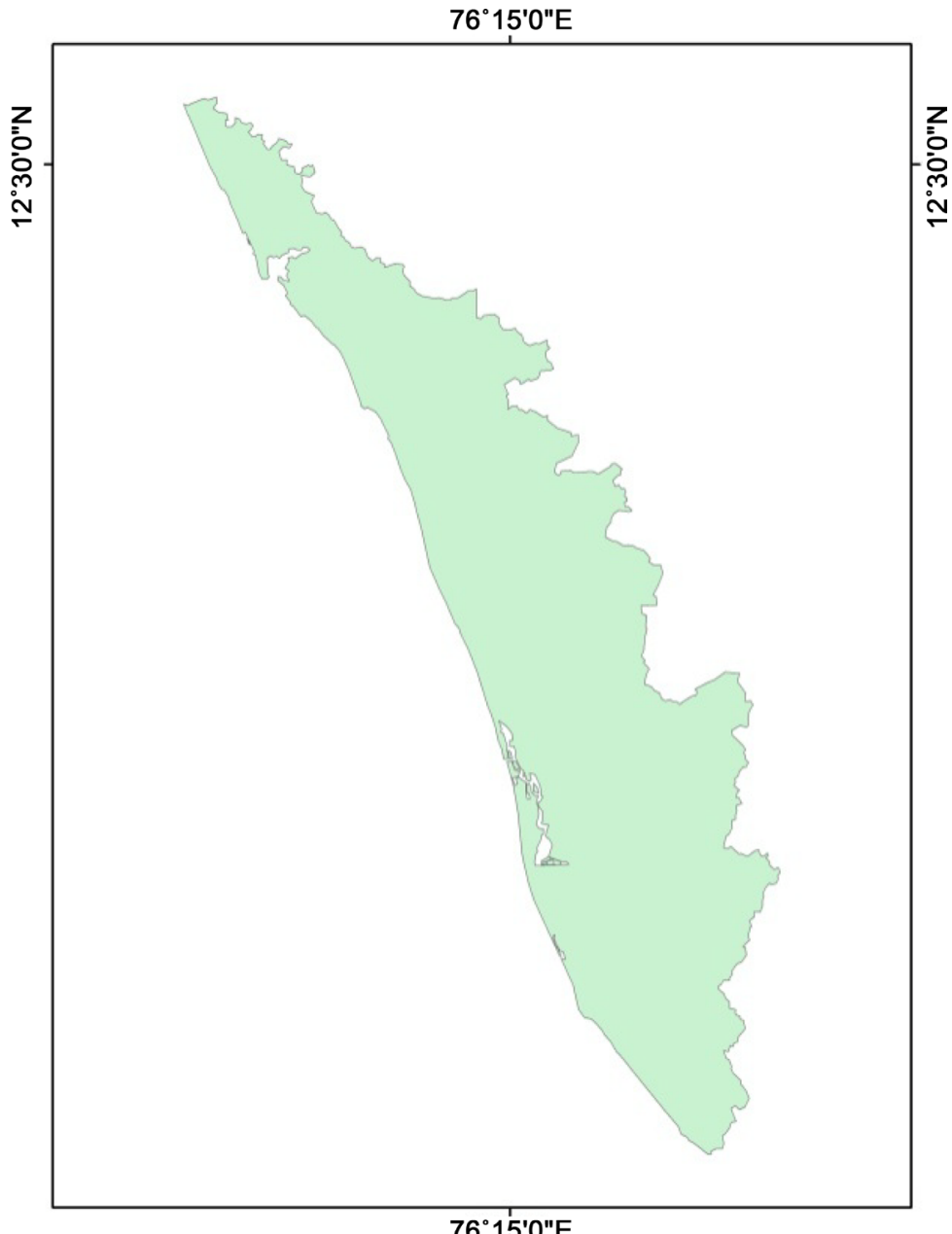

Figure 1. Study area (Kerala with Vembanad Lake).

different seasons observed in this tropical monsoon-influenced environment. Usually three seasons are identified in Kerala, namely pre-monsoon (February May), monsoon (June - August and October - December) and post-monsoon (December - January) [11].

\subsection{Sample Collection}

Ten sampling stations were identified in the distal zone of the lake, and sampled during pre- (March - April, 2008) and post-monsoon (December, 2007 - January, 2008) seasons to study the variations of clam population in relation to physico-chemical variables (Figure 2). Monsoon season was exempted from sampling on account of unfavourable weather conditions.

Similarly, ten sampling stations were identified in the proximal zone of the estuary, and sampled during pre-monsoon season to study the impact of dredging on the clam population in the estuary (Figure 3).

Sampling was not done during monsoon and post-monsoon season in the dredged area (proximal zone) as dredging was suspended at this time. The distal sampling stations were named $\mathrm{D}_{1-10}$ and $\mathrm{d}_{1-10}$ for the pre and post-monsoon sampling respectively, whereas the proximal stations were named $\mathrm{P}_{1-10}$ for the pre- 


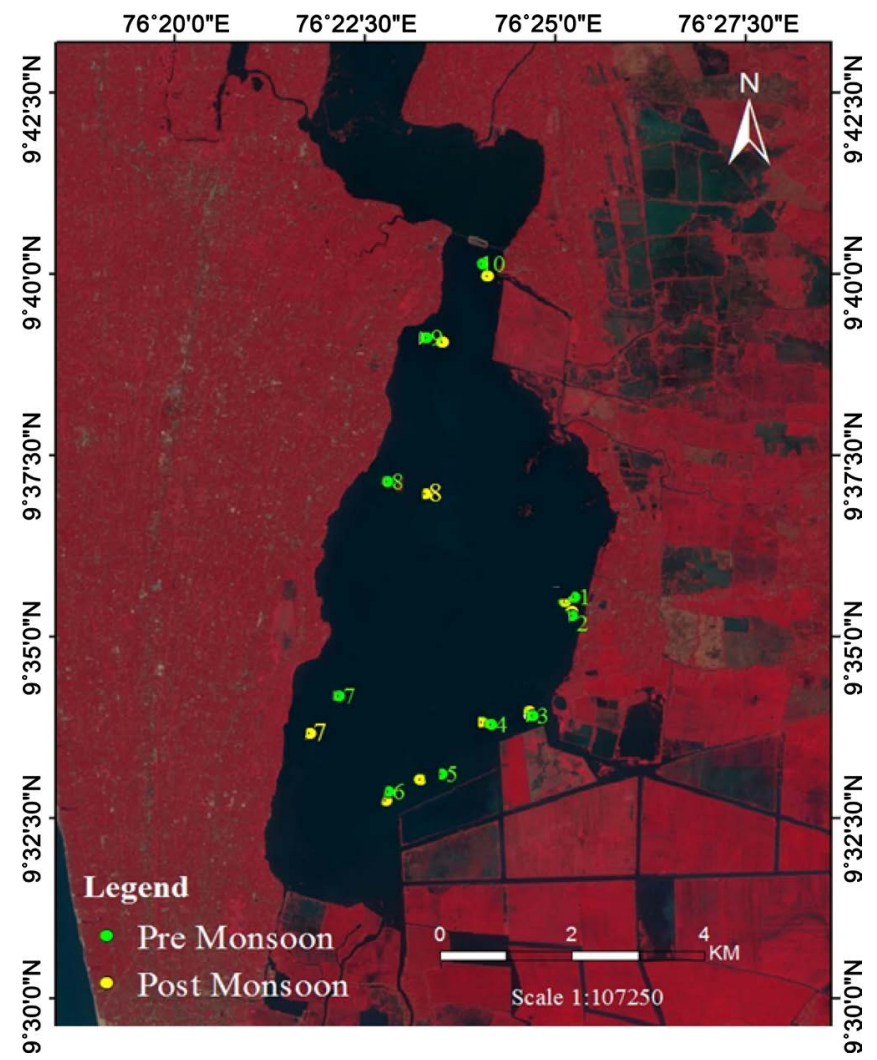

Figure 2. Sampling stations in the distal zone during pre and post monsoon seasons.

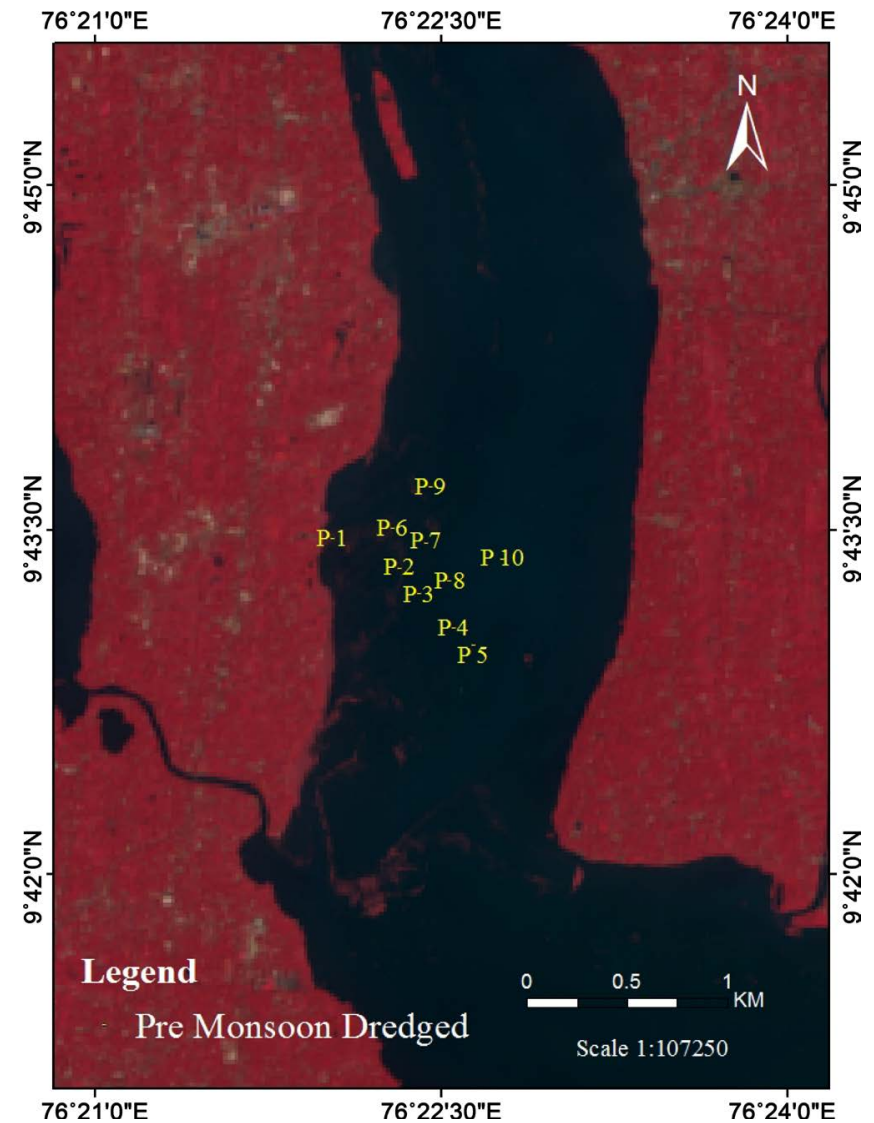

Figure 3. Sampling stations in the proximal zone during pre-monsoon seasons. 
Table 1. Geographic coordinates of the sampling stations.

\begin{tabular}{ccccccc}
\hline & \multicolumn{3}{c}{ Distal Zone } & \multicolumn{2}{c}{ Proximal Zone } \\
\cline { 2 - 7 } & \multicolumn{2}{c}{ Pre-monsoon } & \multicolumn{2}{c}{ Post-monsoon } & \multicolumn{2}{c}{ Pre-monsoon } \\
\hline Stations & Longitude & Latitude & Longitude & Latitude & Longitude & Latitude \\
\hline 1 & 76.4207 & 9.5924 & 76.4188 & 9.5912 & 76.36715 & 9.72436 \\
2 & 76.4202 & 9.5881 & 76.4202 & 9.5888 & 76.37196 & 9.72223 \\
3 & 76.4116 & 9.5651 & 76.4109 & 9.5658 & 76.37341 & 9.72039 \\
4 & 76.4025 & 9.563 & 76.4006 & 9.5634 & 76.37594 & 9.71786 \\
5 & 76.3927 & 9.5517 & 76.3871 & 9.5502 & 76.3773 & 9.71667 \\
6 & 76.3799 & 9.5476 & 76.3797 & 9.5455 & 76.37417 & 9.72444 \\
7 & 76.3691 & 9.5692 & 76.3629 & 9.561 & 76.37391 & 9.72258 \\
8 & 76.3799 & 9.6191 & 76.3883 & 9.6162 & 76.3756 & 9.72131 \\
9 & 76.3883 & 9.6519 & 76.3919 & 9.6512 & 76.375 & 9.728 \\
10 & 76.4006 & 9.6689 & 76.4018 & 9.662967 & 76.377 & 9.726 \\
\hline
\end{tabular}

monsoon sampling. The clams were collected randomly from the sampling stations using a $1 \mathrm{~m} \times 1 \mathrm{~m}$ transect during pre and post-monsoon seasons. Live clams found within the transect were counted in situ and weighed to the nearest gram and maximum width measured to the nearest millimetre in the laboratory. A transect is a square-shaped construct built with iron pipes of half inch thickness. The physico-chemical variables such as temperature and transparency of the water samples were measured at the sampling site where as other environmental variables such as dissolved oxygen, hardness, $\mathrm{pH}$ and salinity were analysed using standard methods [12] in the laboratory. The geographic coordinates of each sampling site were also recorded (Table 1).

\subsection{Multivariate Statistics}

The environmental variables were normalised using the equation

$$
\text { Normalised } X=x-\sum_{i=1}^{n} \frac{x}{n} / \sqrt{\frac{1}{n-1 \sum_{i=1}^{n}\left(x_{i}-x\right)^{2}}}
$$

where $x$ is the variable and $n$ is the sample size, to transform all the variables in proportion to one another. Significant differences, in the hydrographic variables between the proximal and distal zones were investigated using student's $t$ statistics. The dominant variable affecting the clam biomass in proximal and distal zones during pre and post-monsoon seasons was identified using factor analysis. The factor analysis generated the principal components, eigen values, percentage of variance explained by each factor, cumulative percentage of the variance in data explained by inclusion of successive factors and bivariate plots allowing inferences on relations between all variables and their variation. Stepwise regression analysis was also carried out on the variables measured to confirm the critical ecological variable affecting clam distribution in various zones across the seasons. 


\subsection{Remote Sensing Datasets}

The Vembanad estuary is covered in four topographic sheets produced by the Survey of India numbered 58B/4,58B/8,58C/6 and 58C/5 \& C/1 of the year 1967 which are all large-scale maps. Satellite image of the estuary was obtained from LISS-III sensor of IRS-P6 satellite in LGSOWG (Landsat Ground Station Operators Working Group) format. The path, row and map ID of the image obtained are $099,066,58 \mathrm{C} / 6$ and $58 \mathrm{C} / 5 \& \mathrm{C} / 1$. The satellite imagery was processed using ERDAS IMAGINE 8.7 and ArcGIS 9.2.

\subsection{Mapping Protocol}

Protocol used for mapping the distribution of Villorita cyprinoides using environmental variables and satellite image was adopted from [13] (Figure 4). The satellite images retrieved was geo-referenced with the topographic sheets available from Survey of India. The satellite images were then subjected to mosaicking where in the images were combined to form a single image. The mosaicked image was then subjected to image-to-image rectification with the topographic sheet. The visually interpreted and rectified images were then digitised and consequently subjected to inverse distance weighted modelling in conformation with the statistical analyses of the variables. The maps thus obtained of

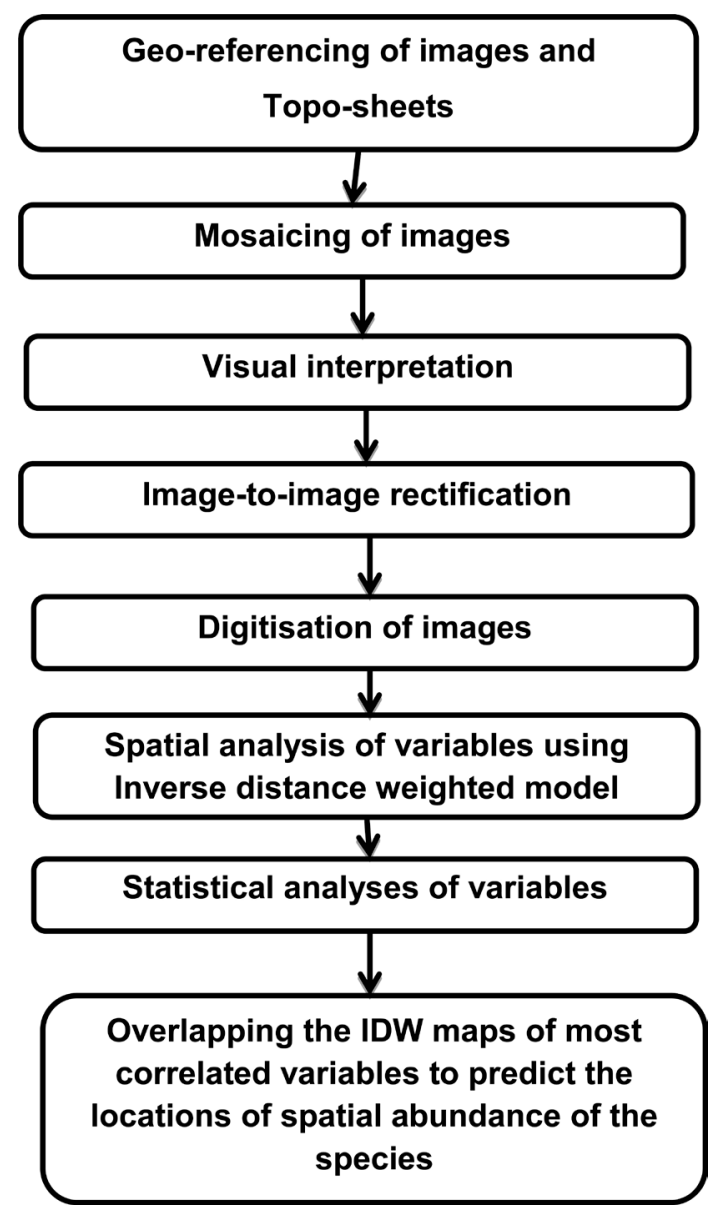

Figure 4. Protocol for mapping the distribution of Villorita cyprinoides. 
the most correlated variables where subjected to overlapping to identify the deterministic variable in clam distribution (Figure 4).

\subsection{Inverse Distance Weighted (IDW) Modelling}

Inverse distance weightage modelling is a spatial interpretation technique of using points with known values to estimate values at other unknown points. This is a type of deterministic method for multivariate interpolation.

\section{Results}

The hydrographic variables of water at sampling stations in the distal fresh-water zone during pre and post monsoon seasons and that of the stations in the proximal brackish water zone during pre-monsoon season is summarised in $\mathrm{Ta}$ ble 2.

T-test on clam biomass during pre and post monsoon seasons in the distal zone indicated a significant difference in the clam biomass between the two seasons $(\mathrm{P}<0.05)$. T-test on hydrographic variables in the distal zone during the sampling periods indicated a significant difference in the environmental variables between the two seasons $(\mathrm{P}<0.05)$. The post-monsoon season in the distal zone showed a higher mean temperature $\left(31.55^{\circ} \mathrm{C} \pm 1.01^{\circ} \mathrm{C}\right)$ in comparison with the pre-monsoon season $\left(31^{\circ} \mathrm{C} \pm 0.53^{\circ} \mathrm{C}\right)$ similar to the results reported earlier [14].

T-test on clam biomass sampled from the proximal and distal zones during the pre-monsoon season showed that there was a significant difference between the two zones. Similarly, T-test on the hydrographic variables sampled from the proximal and distal zones during the pre-monsoon season showed a significant difference between the zones $(\mathrm{P}<0.05)$.

The measurements indicated that mean weight of the clam, Villorita cyprinoides, was more in the distal zone during pre-monsoon season compared with

Table 2. Hydrographic variables at distal and proximal sampling stations during pre and post monsoon seasons.

\begin{tabular}{cccc}
\hline Seasons & Pre-monsoon & Post -monsoon & Pre-monsoon \\
Months & (Mar - Apr'08) & (Dec'07 - Jan'08) & (Mar - Apr'08) \\
Zone & Proximal zone & Distal Zone \\
Area & Dredged area & Non-dredged area & Non-dredged area \\
Mean of the variables/Stations & $\mathrm{P}_{1-10}$ & $\mathrm{~d}_{1-10}$ & $\mathrm{D}_{1-10}$ \\
Temperature $\left({ }^{\circ} \mathrm{C}\right)$ & $31.5 \pm 0.93$ & $31.55 \pm 1.01$ & $31 \pm 0.53$ \\
$\mathrm{pH}$ & $7.9375 \pm 0.42$ & $8.05 \pm 1.21$ & $8 \pm 0.00$ \\
Transparency $(\mathrm{cm})$ & $85 \pm 39.01$ & $305.5 \pm 65.76$ & $129.5 \pm 53.46$ \\
Salinity $(\mathrm{ppt})$ & $9.0375 \pm 0.42$ & $0.34 \pm 0.35$ & $1.75 \pm 1.52$ \\
DO $(\mathrm{ppm})$ & $5.25 \pm 1.59$ & $5.5 \pm 1.54$ & $6.22 \pm 1.73$ \\
Biomass $\left(\mathrm{kg} / \mathrm{m}^{2}\right)$ & $408.5 \pm 340.93$ & $660.66 \pm 565.19$ & $1203.1 \pm 1460.58$ \\
Hardness $(\mathrm{ppm})$ & $16.2125 \pm 0.5$ & & $9.16 \pm 2.61$ \\
\hline
\end{tabular}


Table 3. Length - weight relationship of Villorita cyprinoides in dredged and nondredged areas during pre and post monsoon seasons.

\begin{tabular}{cccc}
\hline Seasons & Pre-monsoon & Post -monsoon & Pre-monsoon \\
\hline Months & (Mar - Apr'08) & (Dec'07 - Jan'08) & (Mar - Apr'08) \\
Zone & Proximal Zone & \multicolumn{2}{c}{ Distal Zone } \\
Area & Dredged area & Non-dredged area & Non-dredged area \\
Stations & $\mathrm{D}_{1-10}$ & $\mathrm{~d}_{1-10}$ & $\mathrm{P}_{1-10}$ \\
Number of samples & 414 & 1140 & 490 \\
Length range of samples (mm) & $1.2-3.6$ & $1.1-5.0$ & $1.4-3.8$ \\
Mean length (mm) & 2.12 & 2.40 & 2.56 \\
Weight range of samples (g) & $0.8-22.69$ & $1.01-31.64$ & $1.08-20.86$ \\
Mean weight $(\mathrm{g})$ & 6.02 & 9.41 & 8.85 \\
\hline
\end{tabular}

Table 4. Variable loadings for the hydrographic variables in the distal zone.

\begin{tabular}{cccc}
\hline Variables & Factor $\mathbf{1}$ & Factor 2 & Factor 3 \\
\hline Temperature & -0.19 & -0.11 & 0.18 \\
$\mathrm{pH}$ & 0.05 & 0.10 & 0.49 \\
Transparency & 0.01 & 0.62 & 0.35 \\
Salinity & 0.21 & -0.12 & -0.36 \\
DO & -0.02 & 0.68 & 0.04 \\
Hardness & 0.95 & -0.28 & 0.11 \\
Biomass & 0.79 & 0.50 & -0.34 \\
Eigen Values & 1.76 & 1.51 & 1.11 \\
\% Cumulative variation & 27.43 & 50.98 & 68.33 \\
\hline
\end{tabular}

that in the proximal zone where dredging was carried out (Table 3).

The factor analysis for the pre and post-monsoon seasons in the distal zone of Vembanad estuary (Table 4) indicated that the first three factors explained $68.33 \%$ of cumulative variations in the variables measured, with eigen values of $1.76,1.51$ and 1.11 respectively. The first factor used in the analysis of environmental variables and clam biomass in the pre and post monsoon season in the distal zone identified that hardness, salinity and $\mathrm{pH}$ are positively correlated with clam biomass and distribution. For the first factor developed in this analysis, hardness showed the highest positive loadings (0.95) followed by salinity (0.21). In the second factor, DO showed a moderate positive correlation (0.68) with clam biomass followed by transparency (0.62). In the third factor, $\mathrm{pH}(0.49)$ had the highest loadings. Temperature is negatively correlated to clam biomass and distribution. Water temperature showed a negative correlation with salinity because of the large amount of freshwater run-off that occurred during pre-monsoon period.

The bivariate plot (Figure 5) indicated that, though the clam biomass had a positive correlation with hardness in the distal zone, the impact of dissolved 


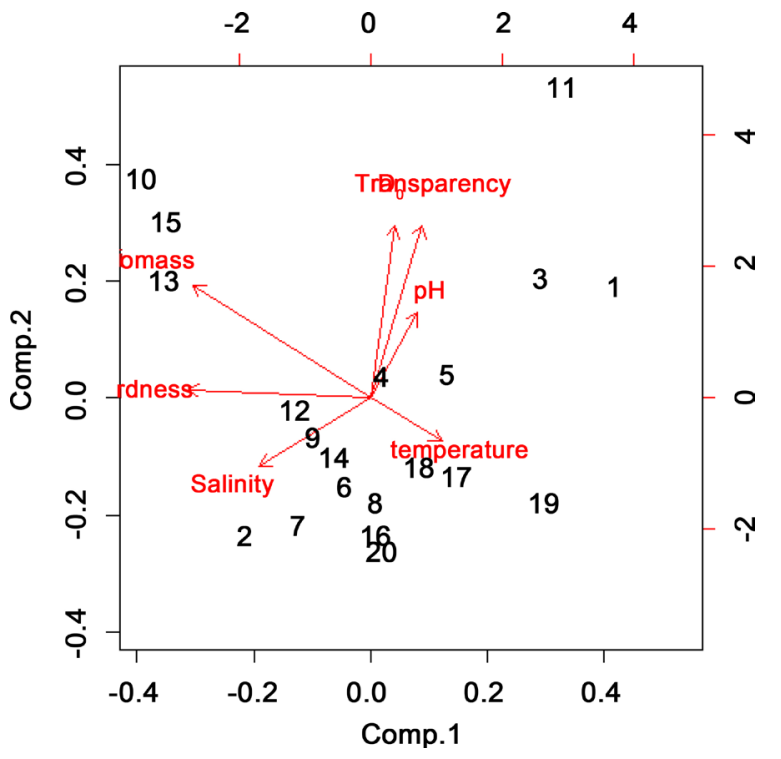

Figure 5. Bivariate plot of variables in the distal zone during pre- and post-monsoon sampling.

oxygen and transparency on the second factor and that of salinity on the first factor could not be ruled out as a determinant of the clam distribution in the distal zone (Table 4). The step wise regression analysis of variables identified a combination of salinity, temperature and DO with adjusted $\mathrm{R}^{2}$ value of 0.125 indicating their pivotal roles in influencing clam biomass. The relationship between the clam biomass and these hydrographic variables are represented using the equation

$$
\begin{aligned}
\text { Clam biomass }(\mathrm{Y})= & -4.512 \mathrm{e}-18-3.136 \mathrm{e}-1 \text { temperature }+3.187 \mathrm{e} \\
& -1 \text { Salinity }+3.415 \mathrm{e}-1 \mathrm{DO}
\end{aligned}
$$

The mean dissolved oxygen observed in these stations during pre and post monsoon seasons in the distal zone were similar to earlier observations [15] [16]. The variations in this hydrographic variable may be due to the influence of primary production in the stations. The mean DO was higher in pre-monsoon season (Table 2) which may be linked to the increased primary production during this period due to the possible optimum light intensity and the effective utilisation of nutrients by phytoplankton that were brought into the estuary along with freshwater. The low DO during post-monsoon season was similar to earlier observations, which may be due to the low primary production in the lake on account of high stratification [15]. The mean salinity during pre-monsoon was more compared to that in the post monsoon season which is similar to the results reported earlier [15]. The salinity was graduating towards the proximal zone where the brackish water is dominant. The zero salinity as experienced in the distal zone of the lake during post-monsoon at station $\mathrm{d}_{1}$ and $\mathrm{d}_{3}$ is due to the freshwater influx from the tributary of the pampa river.

Since dredging was taking place on the distal side (northern side of the bund) and not in the proximal zone, there was a possibility that the variation in clam biomass and the associated hydrographic variables in the distal might be differ- 
ent from the proximal zone.

The factor analysis of variables during the pre-monsoon season in the distal and proximal zone of the estuary indicated that the first three factors explained $72.10 \%$ of the cumulative variations in the variables measured, with eigen values of 2.18, 1.32 and 1.15 respectively (Table 5). The factor analysis of the environmental variables and clam biomass in the distal and proximal zone during pre-monsoon season identified that DO (0.98) had the highest loadings in the first factor. In the second factor, hardness with loadings of $(-0.85)$ had negative correlation with clam biomass whereas transparency $(0.68)$ had the highest positive loadings (Table 5). $\mathrm{pH}$ (0.99) had the highest loadings on the third factor. The bivariate plot (Figure 6) revealed that though DO was the only variable positively correlated to clam biomass, the highest loadings of transparency and $\mathrm{pH}$ on the second and third factor respectively and negative loadings of hardness

Table 5. Variable loadings for the hydrographic variables during pre-monsoon period.

\begin{tabular}{cccc}
\hline Factor loadings & Factor-1 & Factor-2 & Factor-3 \\
\hline Temperature & -0.03 & 0.39 & 0.07 \\
$\mathrm{pH}$ & -0.05 & 0.06 & 0.99 \\
Transparency & 0.39 & 0.68 & 0.12 \\
Salinity & 0.28 & -0.29 & 0.14 \\
DO & 0.98 & 0.16 & 0.11 \\
Hardness & -0.12 & -0.85 & 0.12 \\
Biomass & 0.61 & 0.07 & -0.27 \\
Eigen values & 2.18 & 1.32 & 1.15 \\
\% cumulative variation & 33.77 & 54.24 & 72.10 \\
\hline
\end{tabular}

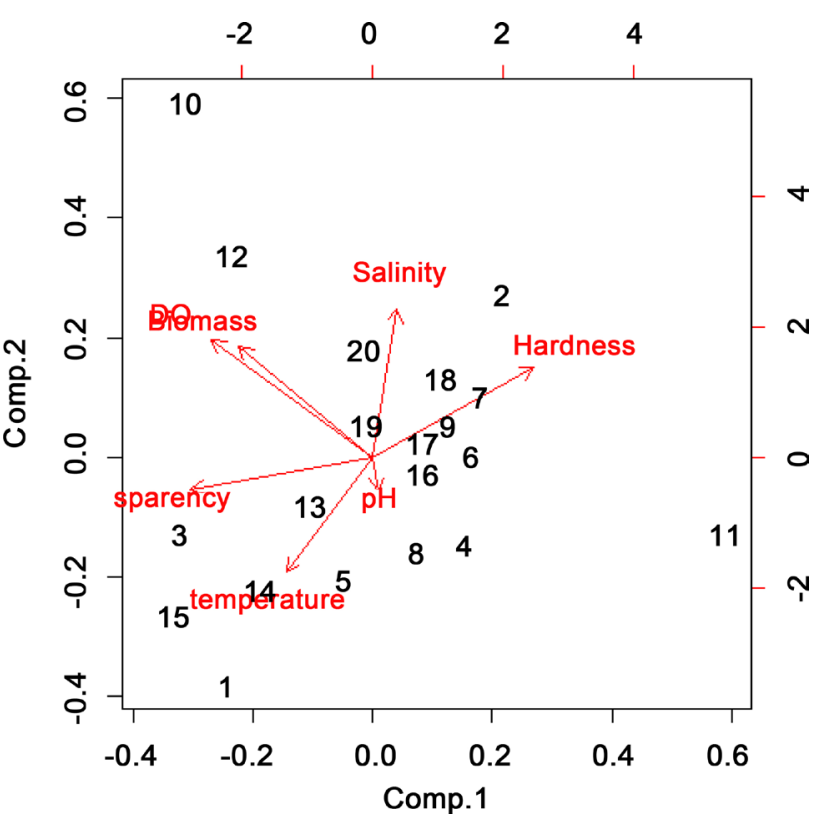

Figure 6. Bi-variate plot of variables during the pre-monsoon season in the distal and proximal zone. 
in the second factor may influence the clam distribution during pre-monsoon period in proximal and distal zones of the lake. The decreased transparency due to dredging during pre-monsoon period and the consequent reduction in clam biomass could be observed. The stepwise regression revealed that DO and salinity act as crucial variables influencing biomass and distribution of clams as in the Equation (2) (Adjusted $\mathrm{R}^{2}=0.3$ ) as

$$
\text { Clam biomass }(\mathrm{Y})=-2.428 \mathrm{e}-18+1.253 \mathrm{e}-1 \text { Salinity }+6.111 \mathrm{e}-1 \mathrm{DO}
$$

Water transparency and temperature showed a negative correlation during pre-monsoon analysis. This may be due to the highly turbid water at the proximal zone, which is a dredging site and the high mean water temperature during the season. Similar results were observed previously by [17]. Since solubility of oxygen is inversely proportional to temperature, a negative relationship was observed between temperature and dissolved oxygen during pre-monsoon. Hardness showed a negative correlation with salinity and a positive correlation with transparency in the second factor consistent with [18]. The first factor clearly represented the positive correlation between dissolved oxygen and clam biomass as explained by [17]. The bivariate plots indicated that saline water and good DO are responsible for the survival of clams as observed earlier by [19].

\section{Discussion}

Environmental variables such as temperature, $\mathrm{pH}$, dissolved oxygen, transparency and hardness are important in deciding the distribution of an aquatic species [20] [21]. [15] identified salinity as the lone variable determining clam distribution in Vembanad estuary. But, the present study showed that other environmental variables such as dissolved oxygen, salinity and temperature are also responsible in determining clam distribution. The factor analysis indicated that dissolved oxygen, temperature and salinity were important in the distal zone during pre and post-monsoon periods whereas dissolved oxygen and salinity were the important during pre-monsoon period in the distal and proximal zones. These observations were mapped on a GIS platform using inverse distance model to interpret the results spatially.

The predominance of dissolved oxygen over salinity and temperature as represented in the bivariate plot (Figure 5 and Figure 6) determined the spatial distribution of clam biomass during pre and post monsoon in distal zone. Dissolved oxygen showed greater affinity towards the tributary sink and bund region in spatial maps, probably because of increased turbulence at the sink point and water exchange at the bund opening during pre (Figure 7) and post-monsoon (Figure 8) seasons in the distal zone. The IDW model of salinity, in the distal zone during pre (Figure 9) and post monsoon (Figure 10), showed lower salinity in the south (freshwater) and an increasing gradient towards the north to approximate marine conditions at the proximal end [18]. The marked decrease in salinity during post monsoon in the distal zone was very consistent with earlier observations [15]. Since there is no marked variation in temperature across the 


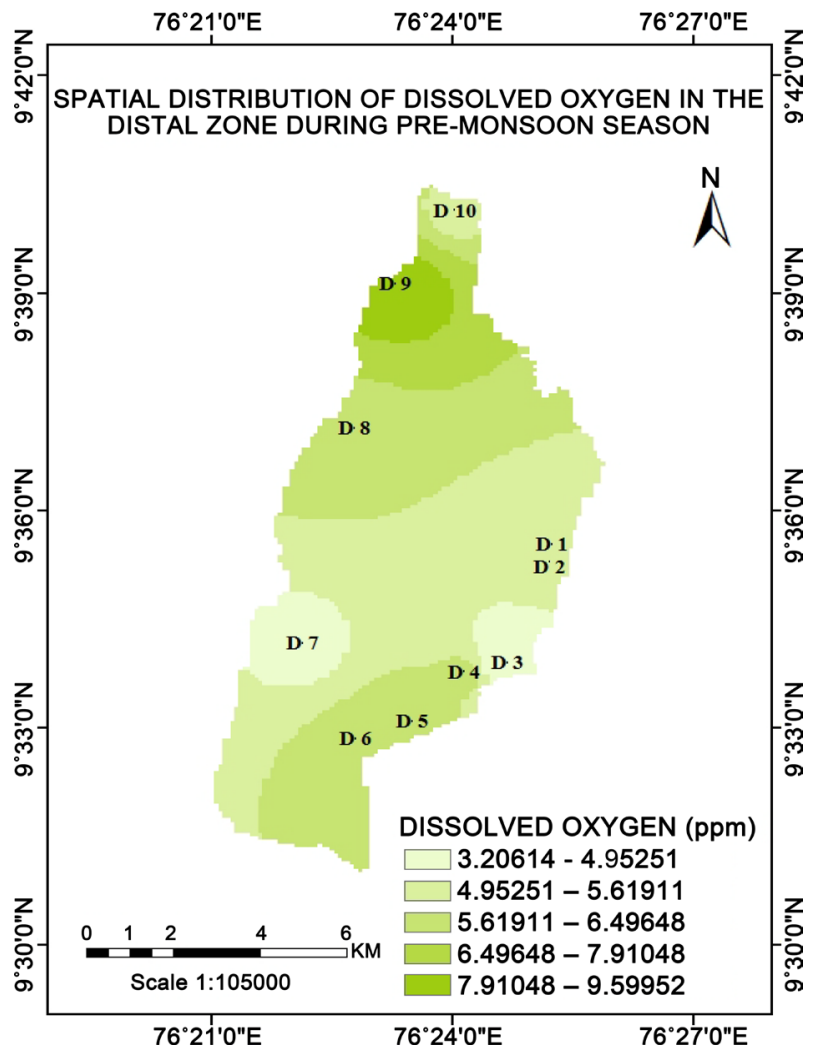

Figure 7. Inverse distance weightage model of dissolved oxygen in the distal zone during pre-monsoon.

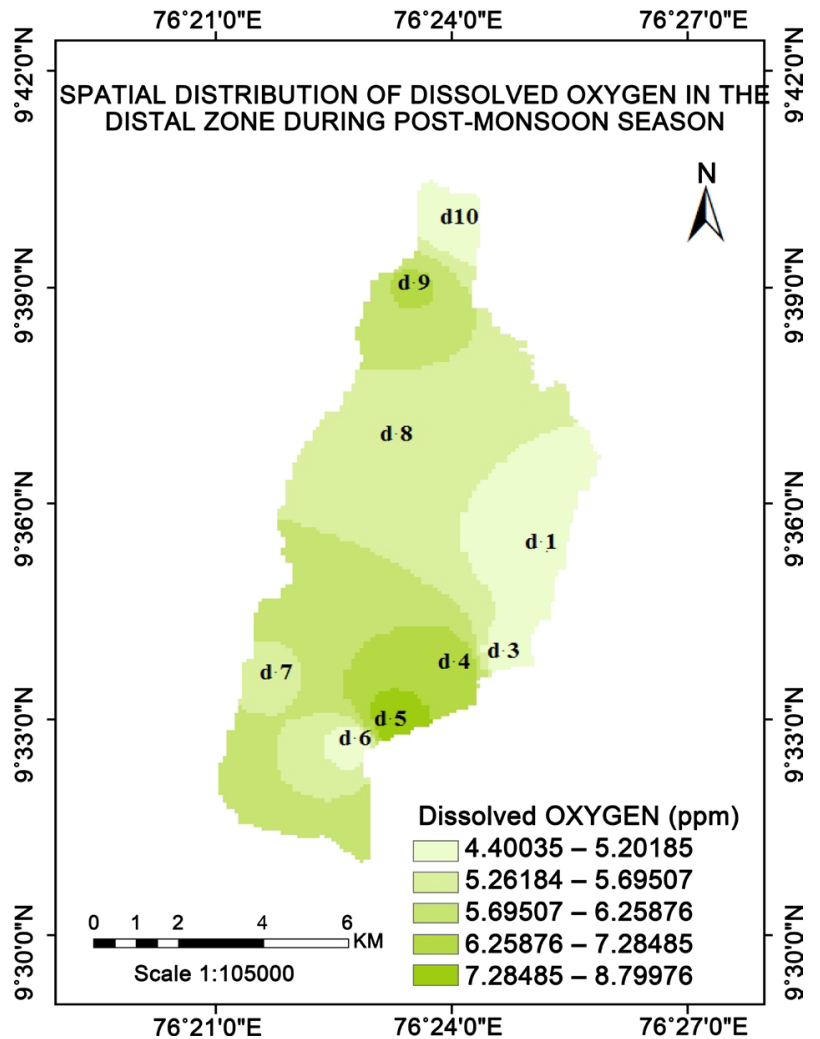

Figure 8. Inverse distance weightage model of dissolved oxygen in the distal zone during post-monsoon. 


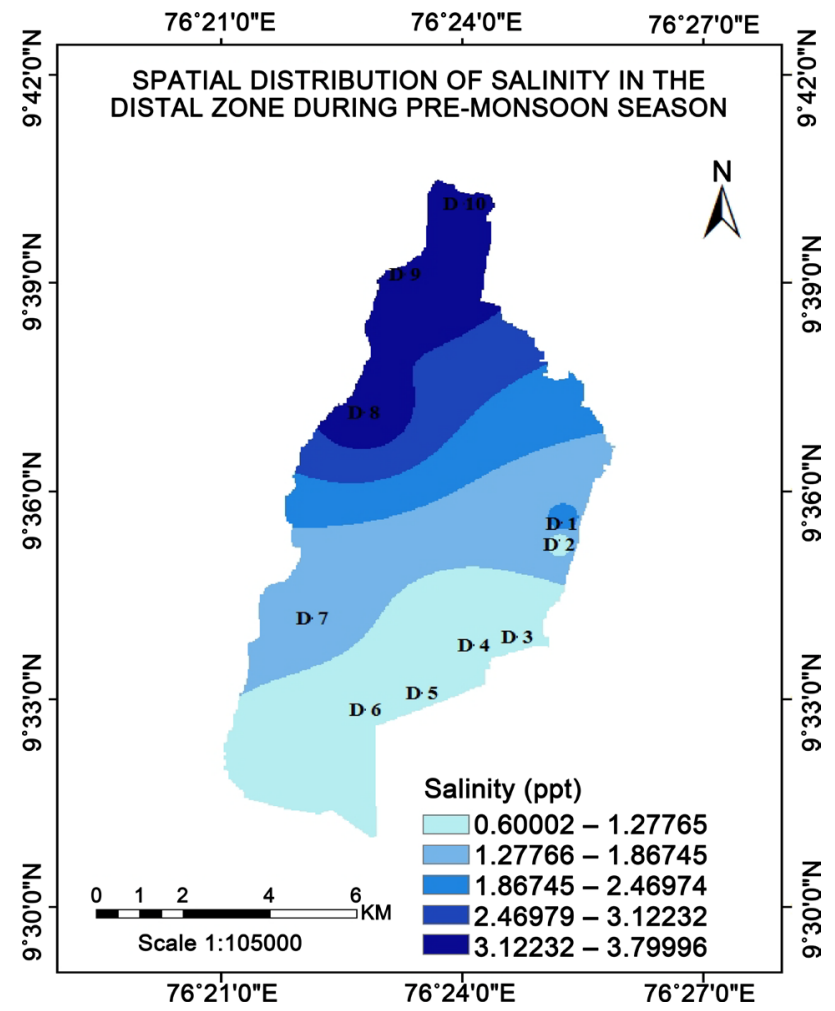

Figure 9. Inverse distance weightage model of salinity in the distal zone during premonsoon.

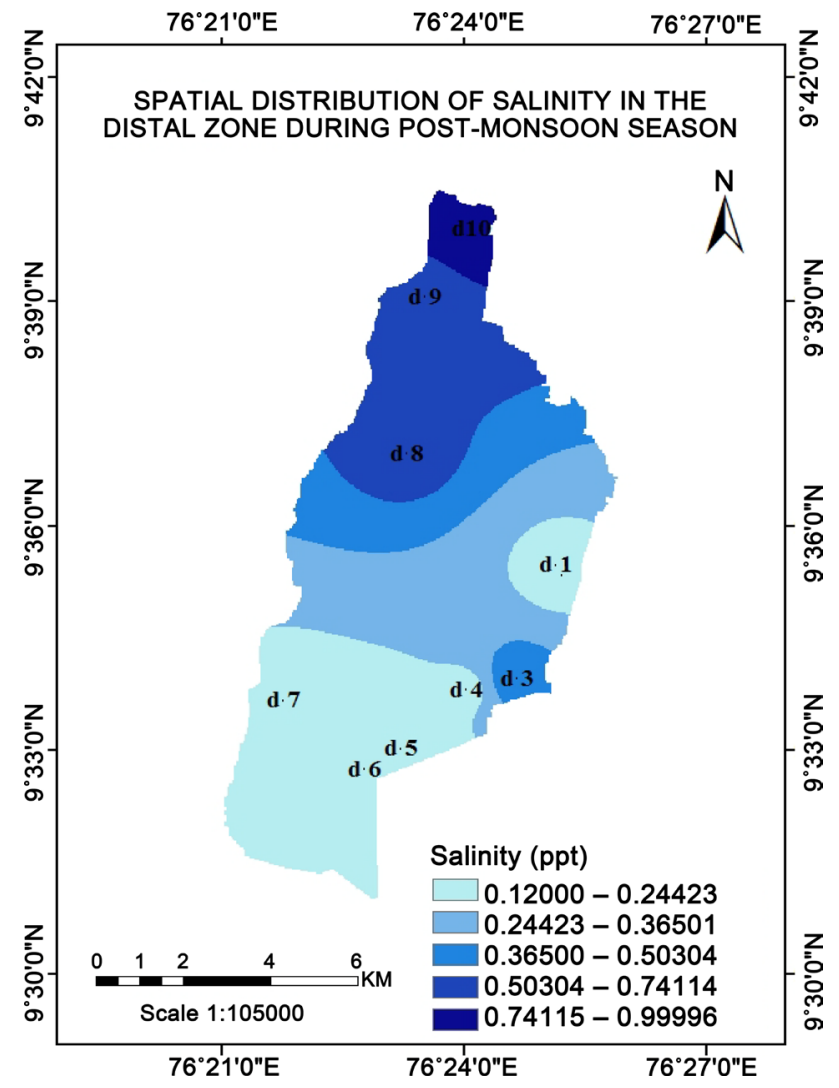

Figure 10. Inverse distance weightage model of salinity in the distal zone during postmonsoon. 
distal zone in the estuary, IDW of temperature was not prepared. IDW model of clam biomass in distal zone in pre-monsoon (Figure 11) was also prepared. The IDW model of clam distribution (Figure 12) during post monsoon in distal zone showed a gradually increasing trend towards south east zone of the estuary where a tributary of Pamba river enters the estuary. The IDW of clam biomass follows a similar pattern of spatial distribution of dissolved oxygen in the distal zone during pre and post monsoon season.

The spatial variation of the dissolved oxygen in the proximal zone during pre-monsoon season showed that dissolved oxygen in the proximal zone was low, on account of low transparency due to dredging as well as the suspension of dredged materials due to entrenchment. The dissolved oxygen was minimum near the dredger and it gradually increased away from the dredger as observed in Figure 13.

Figure 14 represents the spatial distribution of salinity in the proximal zone. The IDW model for salinity (Figure 14) showed a marked increase in salinity towards proximity where the estuary converges with the Arabian Sea, as reported earlier by [15]. The IDW model of DO in proximal zone (Figure 13) indicated that $\mathrm{DO}$ of the water gradually increased away from the dredge site. The IDW model of clam distribution (Figure 15) showed that the biomass was negligible near the dredging site and increased gradually away from the dredger conforming to the results obtained from bivariate plot (Figure 6). This is mainly due to the mortality of clams subjected to smothering due to entrenchment at these sites along with low transparency and DO. Due to various water and wind movements, the entrenched sediments are carried towards the proximal zone of the lake causing sedimentation of the dredged materials, smothering the live clams and thereby reducing survival rate.

The IDW representation of clam distribution in various seasons and zones indicated a parallel shift in the clam distribution in relation to the environmental variables emphasising the predominant role of the latter in determining availability of the species. The suitable habitat sites for clams during various seasons in the distal zone were identified using the IDW models of salinity and DO in distal zone during pre (Figure 16) and post monsoon season (Figure 17).

The IDW representation of clam distribution in various seasons and zones indicated a parallel shift in the clam distribution in relation to the environmental variables emphasising the predominant role of the latter in determining availability of the species. The suitable habitat sites for clams during various seasons in the distal zone were identified using the IDW models of salinity and DO in distal zone during pre (Figure 16) and post monsoon season (Figure 17).

The predictive spatial distribution map of clam abundance in the distal zone during pre-monsoon season (Figure 16) obtained by overlaying the environmental variables such as dissolved oxygen and salinity was similar to the results from IDW model of clam biomass in distal zone (Figure 11). The predominance of DO over salinity as represented in the bivariate plot (Figure 5) was reflected both in the predictive map and the IDW model of clam abundance in the distal 


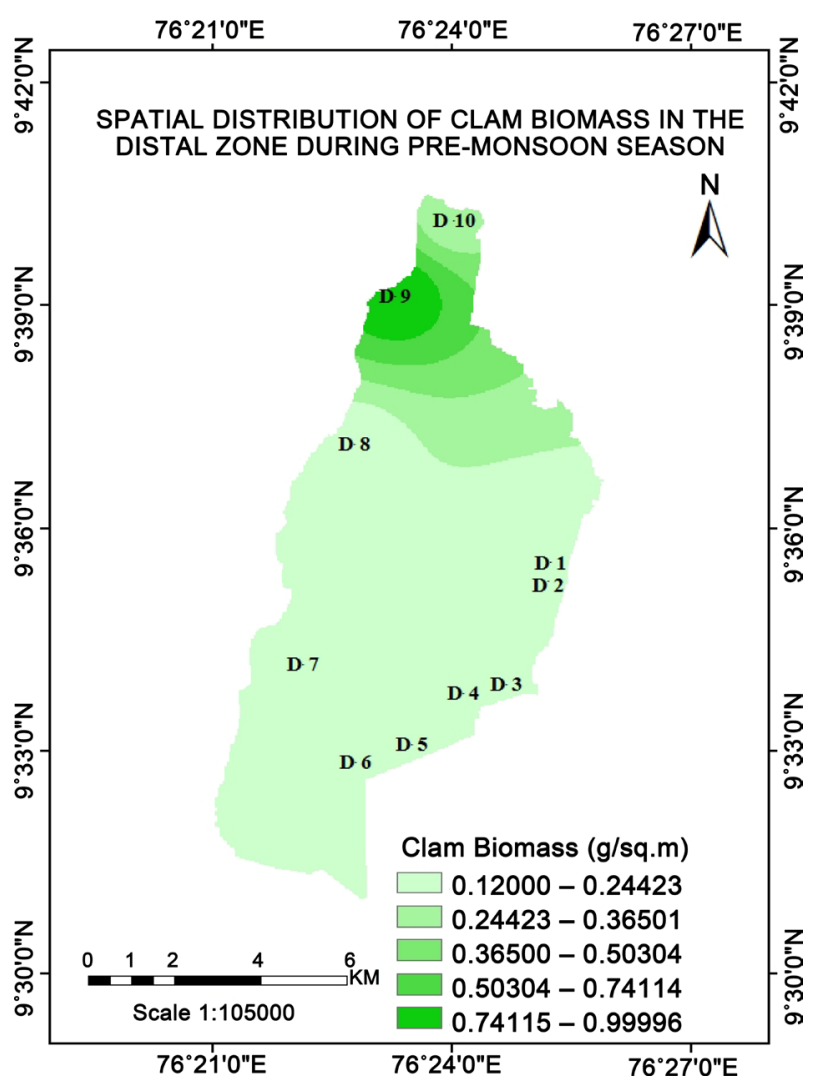

Figure 11. Inverse distance weightage model of clam biomass in the distal zone during pre-monsoon.

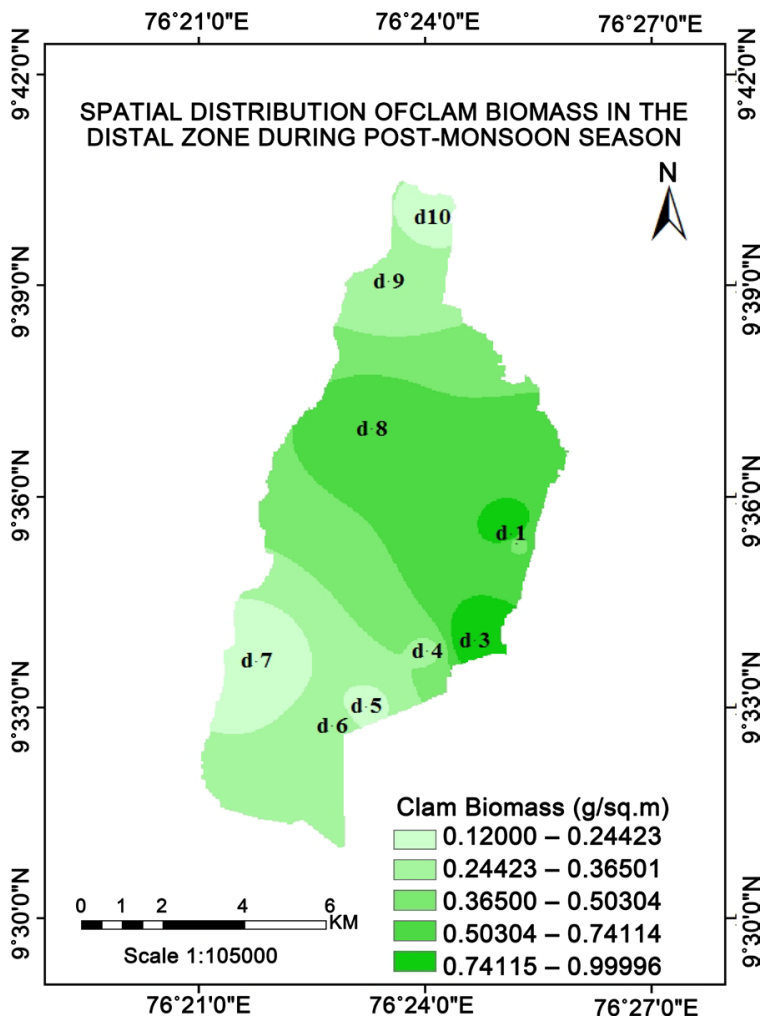

Figure 12. Inverse distance weightage model of clam biomass in the distal zone during post-monsoon. 


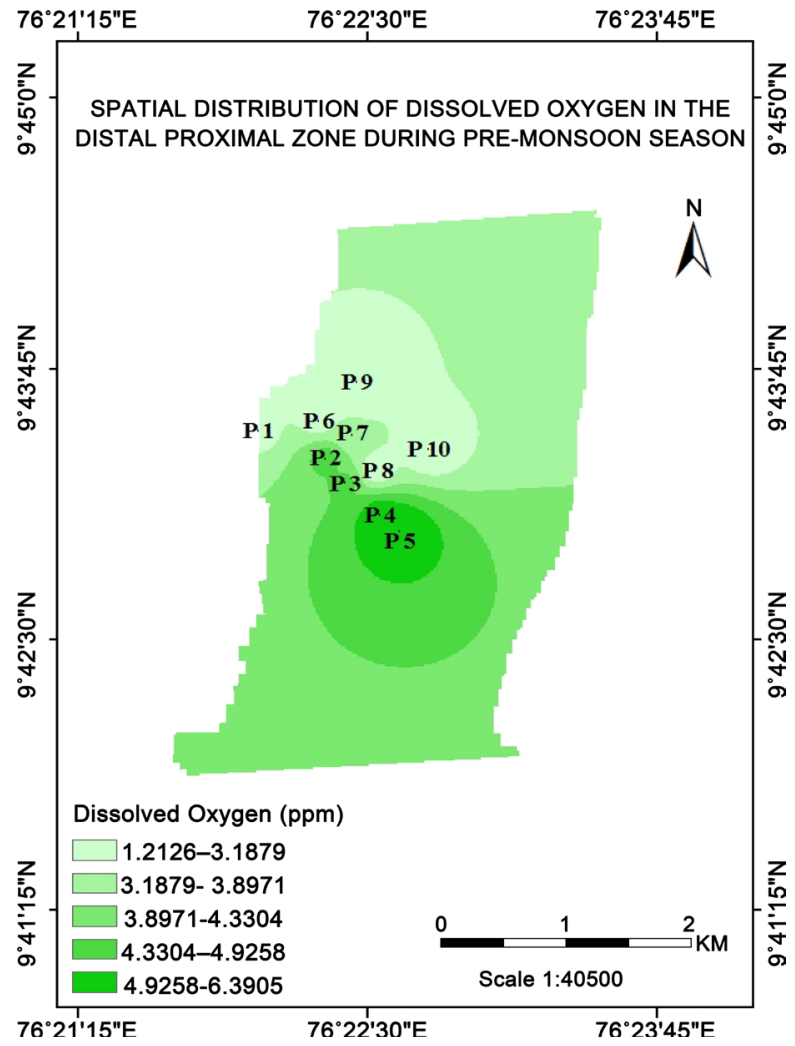

Figure 13. Inverse distance weightage model of dissolved oxygen in the proximal zone during pre-monsoon.

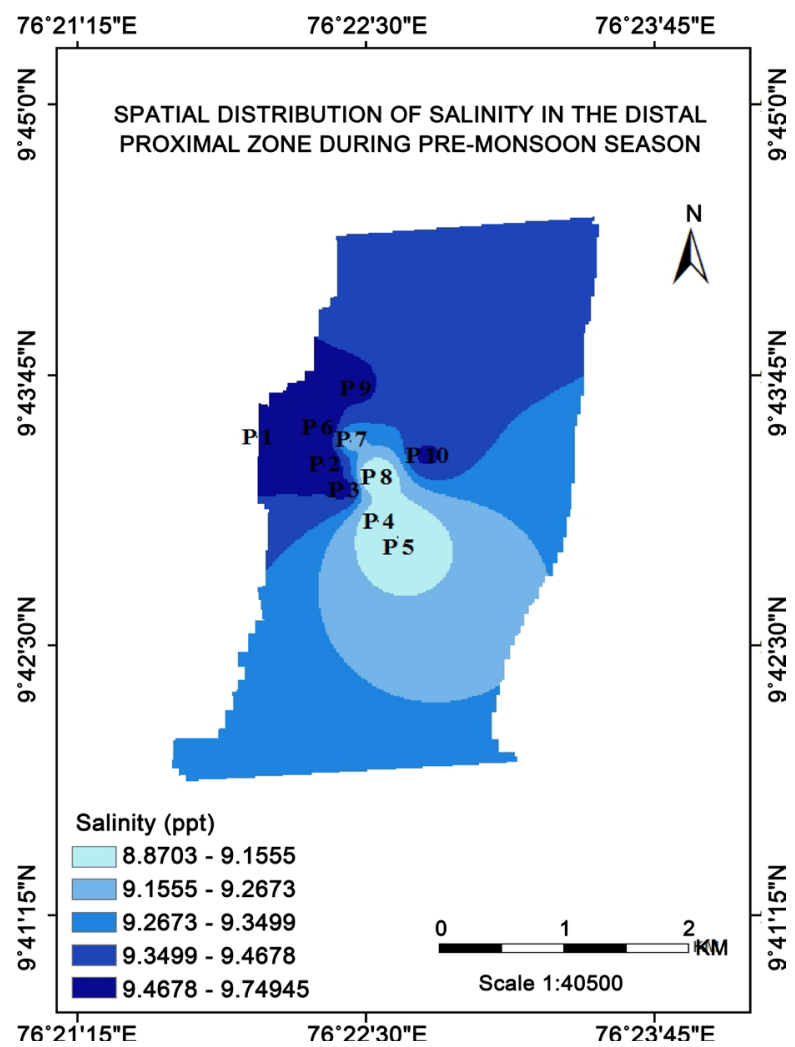

Figure 14. Inverse distance weightage model of salinity in the proximal zone during pre-monsoon. 


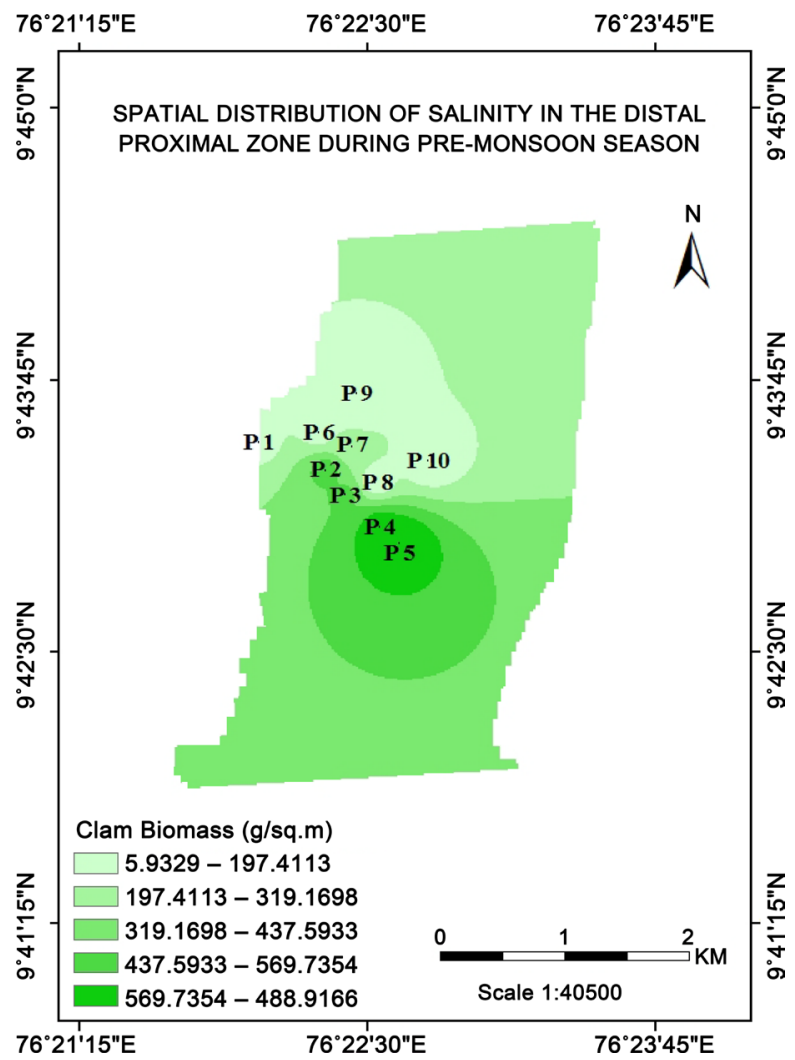

Figure 15. Inverse distance weightage model of clam biomass in the proximal zone during pre-monsoon.

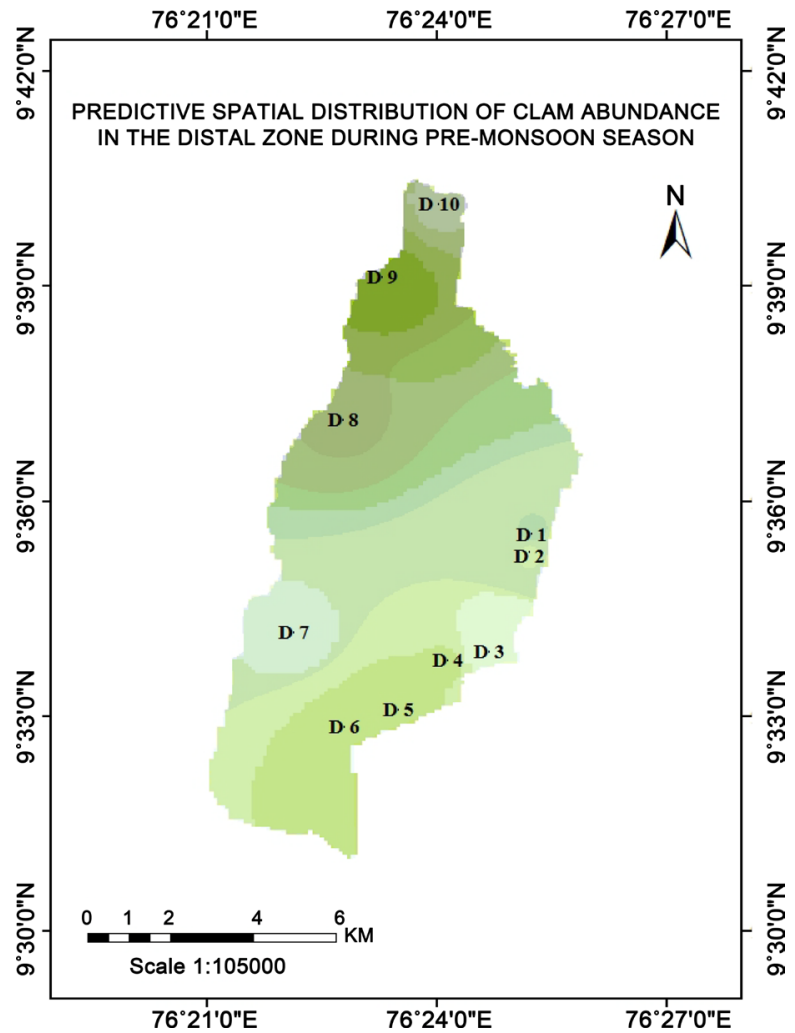

Figure 16. Predictive spatial distribution of clam abundance in the distal zone during pre-monsoon. 


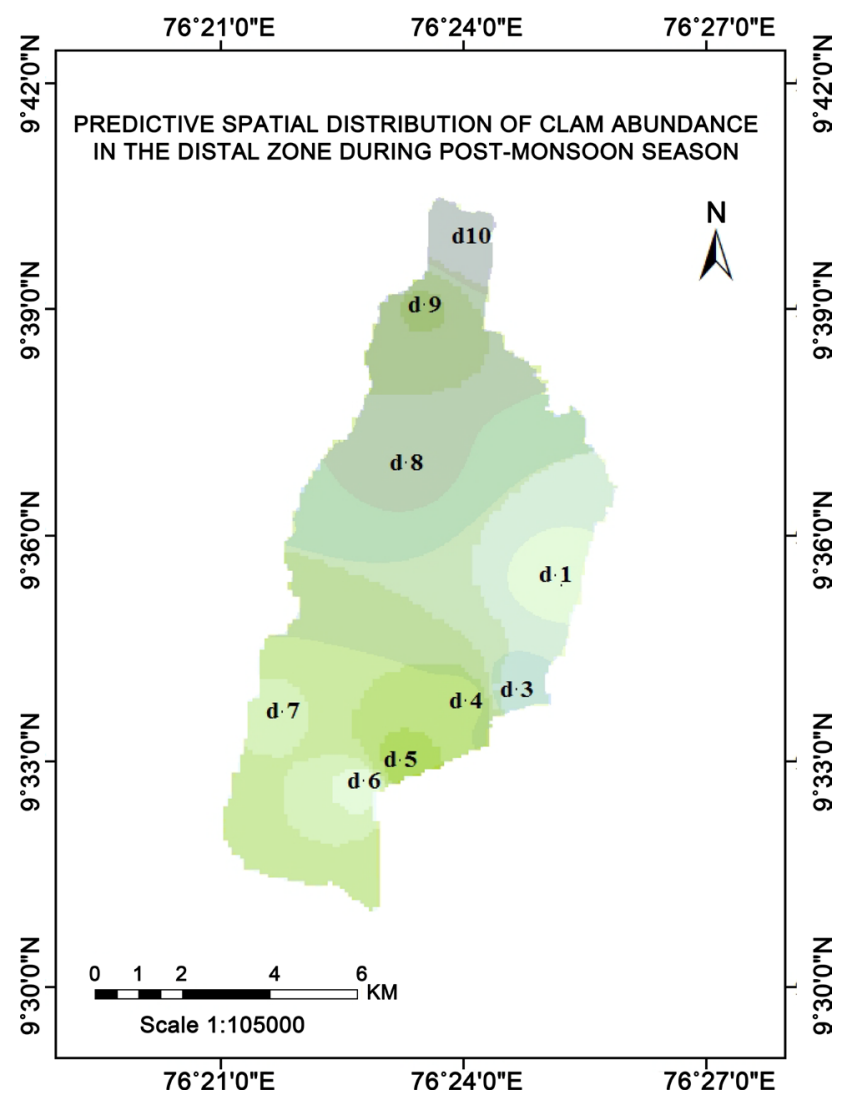

Figure 17. Predictive spatial distribution of clam abundance in the distal zone during post-monsoon.

zone during pre-monsoon season (Figure 11).

Similarly, the predictive spatial distribution map of clam abundance in the distal zone during post monsoon season (Figure 17) obtained by overlaying the correlated environmental variables was similar to the IDW model of clam biomass in distal zone during post-monsoon season (Figure 12). The predominance of DO over salinity could not be observed in the predictive map, or in the inverse distance weighted model of clam abundance, but a combined effect of the variables were observed in the predictive and IDW maps of clam abundance.

The crucial role of dissolved oxygen in clam distribution during pre-monsoon in proximal zone as represented in bivariate plot (Figure 13) was reflected in the IDW model in distal zone during post monsoon (Figure 13). The predictive spatial distribution map of clam biomass (Figure 18) is similar to the IDW model (Figure 15). These predictive models not only identified suitable sites for clam growth as well as survival, but also helped in visualising spatially the impact of dredging on the clam biomass in the proximal zone of the estuary.

Most of the previous studies related to mapping of molluscan resources were used for identification of suitable sites for aquaculture, habitat mapping etc. But they failed in representing the seasonal dominant variables for predicting the biomass of clams and its fishery (Table 6).

The study is first of its kind, which attempts to map the clam distribution based on the responses to environmental variables and dredging. The study 


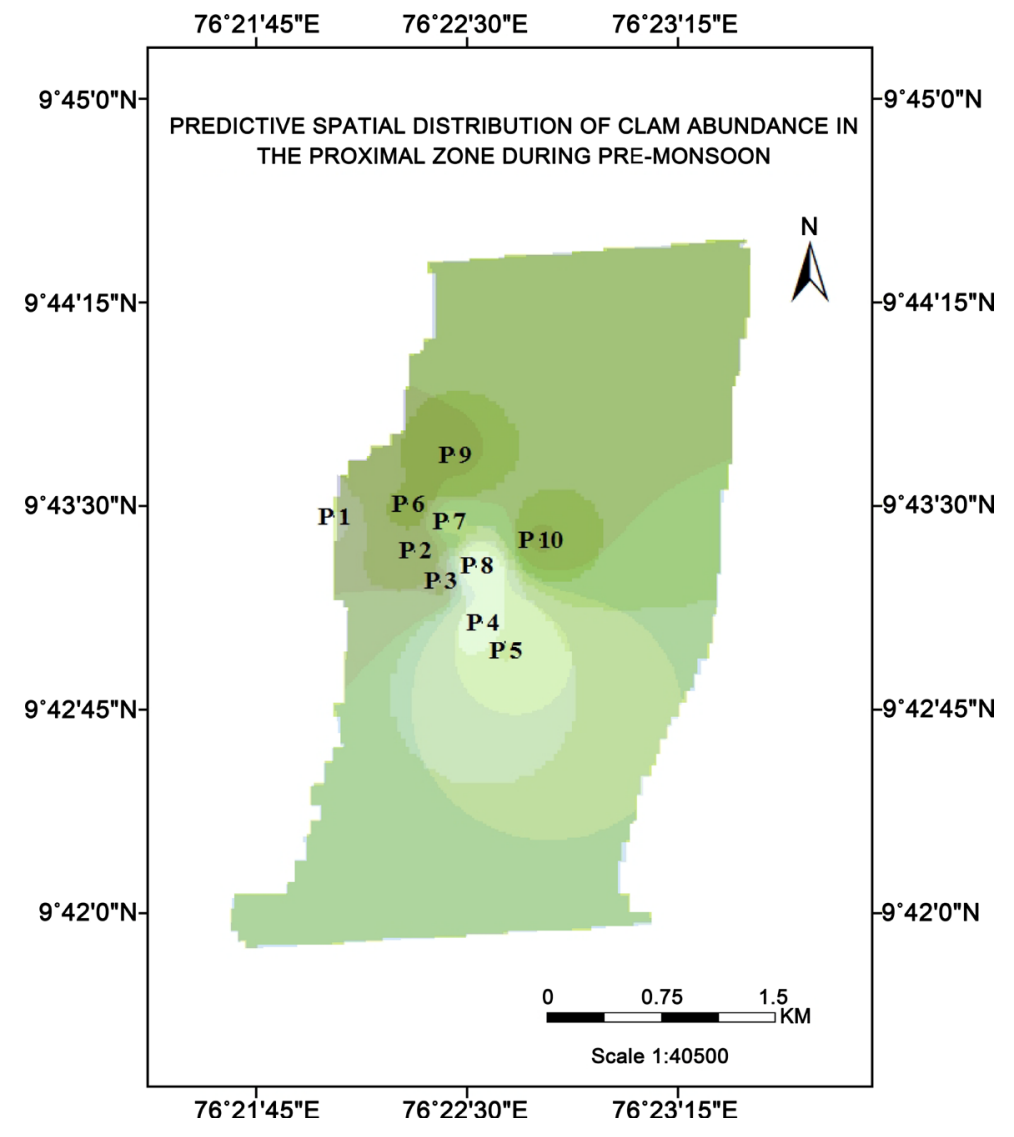

Figure 18. Predictive spatial distribution of clam abundance in the proximal zone during pre-monsoon.

Table 6. Studies related to GIS and Molluscan mapping with the criterion for mapping and variables used.

\begin{tabular}{|c|c|c|}
\hline Major activities during the study & Research output & Reference \\
\hline $\begin{array}{l}\text { Development of a data driven method for } \\
\text { identifying areas most suitable for hard clam } \\
\text { aquaculture in Florida USA using GIS and SRS. }\end{array}$ & $\begin{array}{l}\text { Identified areas of the Indian River Lagoon on the } \\
\text { Florida east coast and Charlotte Harbor on the } \\
\text { Florida west coast that suits hard clam aquaculture }\end{array}$ & [22] \\
\hline $\begin{array}{l}\text { Development of an optimum location selection } \\
\text { technique to transfer mangrove oyster Crassostrea } \\
\text { rhizophorae raft culture technology to selected } \\
\text { coastal communities in Margarita Island, } \\
\text { Venezuela. }\end{array}$ & $\begin{array}{l}\text { Multiple Criteria Evaluation was used to generate } \\
\text { a map of the optimum sites for oyster aquaculture }\end{array}$ & [23] \\
\hline $\begin{array}{l}\text { Building up a spatial database using those criteria } \\
\text { which were considered to have any influence in } \\
\text { integrating marine fish-cage culture within the } \\
\text { tourism industry in Tenerife (Canary islands). }\end{array}$ & $\begin{array}{l}\text { Three model Criteria (distance to beaches, } \\
\text { nautical sports, and view shed), which were } \\
\text { mapped to show the most suitable areas for cage } \\
\text { culture development in coexistence with tourism }\end{array}$ & [24] \\
\hline $\begin{array}{l}\text { Identification of the most suitable sites for } \\
\text { hanging culture of Japanese scallop using } \\
\text { geographic information system (GIS)-based } \\
\text { multi-criteria evaluation models }\end{array}$ & $\begin{array}{l}\text { A series of GIS models was developed to identify } \\
\text { the most suitable areas for scallop culture using } \\
\text { weighted linear combination }\end{array}$ & [25] \\
\hline $\begin{array}{l}\text { Identify the zones of high clam abundance and } \\
\text { develop a model to explain the impact of } \\
\text { environmental variables and dredging on clam } \\
\text { biomass in an estuary }\end{array}$ & $\begin{array}{l}\text { Developed GIS based IDW-model for the } \\
\text { temporal clam biomass distribution in the } \\
\text { Vembanad estuary and also during dredging } \\
\text { identifying the dominant variable controlling the } \\
\text { distribution in each season. }\end{array}$ & $\begin{array}{l}\text { Present study is a combination of } \\
\text { different strategies adopted by the } \\
\text { earlier researchers with a better } \\
\text { mapping protocol based on dominant } \\
\text { variables. [26] }\end{array}$ \\
\hline
\end{tabular}


identified the sites near to dredger and beyond the dredger to a few distances as unsuitable for growth and survival of black clam because the entrenched material gets settled after being carried by the underwater movements at few distances beyond the dredger. This shows that this area is unsuitable for clam growth and even for any clam culture activities in the near future. The area ahead of dredger $\left(\mathrm{P}_{1}\right)$ is depicted as safe from the impacts of dredging. The study also predicted the clam abundance sites in the pre-monsoon and post monsoon season in the distal zone, where in the colour gradient of green exhibited the abundance of clam.

\section{Conclusions}

Monitoring the distribution of clam biomass during different seasons on the basis of environmental variables helps in identifying the availability of the species and monitoring the catches season wise. The study reveals the importance of monsoon-based seasons in the distribution of the species in the estuary. The study indicates a shift in the clam biomass during various seasons. The clam fishery management may be devised based on the spatial abundance and the present study shows a spatial distribution of abundant clam zones for a proper management.

Long-term monitoring programmes are essential for defining protracted trends of environmental degradation or climatic change. Unfortunately, few studies worldwide have considered continuous long-term data. This paucity of information on long-term benthic change prevails in part because of the high expense associated with collecting, sorting, and identifying benthic samples. Such cost constraints lead to compromising over the intensity, distribution, frequency and longevity of a sampling programme. Truly long-term data sets with high spatial and temporal replication are therefore rarely available. The study requires as suggested a data frame over long term in addition to a detailed study on the distribution of the food of the species to comprehend on the exact distribution pattern of the bivalve.

\section{Acknowledgements}

The authors acknowledge the support from Dr. V. R. Suresh, Director, Central Inland Fisheries Research Institute, Dr. A. Gopalakrishnan, Director, Central Marine Fisheries Research Institute, Dr. Dilip Kumar, ex-director of Central Institute of Fisheries education for supporting the work.

\section{References}

[1] Dias, F.J.S., Marins, R.V. and Maia, L.P. (2009) Hydrology of a Well-Mixed Estuary at the Semi-Arid Northeastern Brazilian Coast. Acta Limnologica Brasiliensis, 21, 377-385.

[2] Morrisey, D.J., Howitt, L., Underwood, A.J. and Stark, J.S. (1992) Spatial Variation in Soft-Sediment Benthos. Marine Ecology Progress Series, 81, 197-204. https://doi.org/10.3354/meps081197

[3] Diaz, R.J. and Rosenberg, R. (1995) Marine Benthic Hypoxia: A Review of Its Eco- 
logical Effects and the Behavioural Responses of Benthic Macrofauna. Oceanography and Marine Biology, An Annual Review, 33, 245-303.

[4] Newell, R.C., Seiderer, L.J. and Hitchcock, D.R. (1998) The Impact of Dredging Works in Coastal Waters: A Review of the Sensitivity to Disturbance and Subsequent Recovery of Biological Resources on the Sea Bed. Oceanography and Marine Biology, An Annual Review, 36, 127-178.

[5] CMFRI (2015) CMFRI Annual Report 2014-2015. Technical Report, CMFRI, Kochi.

[6] Sen, D.P. (2005) Advances in Fish Processing Technology. Allied Publishers PVT, Ltd.

[7] Gopal, N., Jeyanthi, P. and Chandrasekar, V. (2014) Production and Marketing of the Black Clam (Villorita cyprinoides) in Perumbalam Island, Alappuzha District, Kerala. Indian Journal of Fisheries, 61, 85-90.

[8] David, R.C. and Kirsty, J.S. (2005) Macrobenthic Community Responses to LongTerm Environmental Change in an East Australian Sub-Tropical Estuary. Estuarine, Coastal and Shelf Science, 63, 315-331.

[9] Thrush, S.F. (1991) Spatial Pattern in Soft-Bottom Communities. Trends in Ecology \& Evolution, 6, 75-79.

[10] Hewitt, J.E., Pridmore, R.D., Thrush, S.F. and Cummings, V.J. (1997) Assessing the Short-Term Stability of Spatial Patterns of Macrobenthos in a Dynamic Estuarine System. Limnology and Oceanography, 42, 282-288. https://doi.org/10.4319/lo.1997.42.2.0282

[11] Harikrishnan, M., Vipin, P.M. and Kurup, B.M. (2011) Status of Exploited Fishery Resources of Azhikode Estuary, Kerala, India. Fish Tech, 48, 19-24.

[12] APHA (American Public Health Association) (1992) Standard Methods for the Examination of Water and Wastewater. 18th Edition, APHA, Washington DC.

[13] Lomeli, K.C. (2011) Correlations between Fish Abundance and Physicochemical Parameters in Humboldt Bay, California. Dissertation, Humboldt State University, Arcata.

[14] Asha, C.V., Cleetus, R.I., Suson, P.S., et al. (2015) Environmental Factors Structuring the Fish Assemblage Distribution and Production Potential in Vembanad Estuarine System, India. International Journal of Marine Science, 5, 1-13.

[15] Pillai, V.K.K., Joseph, K.J. and Nair, A.K.K. (1975) The Plankton Production in the Vembanad Lake and Adjacent Waters in Relation to the Environmental Parameters. Bulletin of the Department of Marine Sciences, 7, 137-150.

[16] Haridas, P., Pratap, M. and Rao, T.S.S. (1973) Salinity, Temperature and Zooplankton Biomass of the Backwaters from Cochin to Alleppey. Indian Journal of Marine Sciences, No. 2, 94-102.

[17] Yung, Y.K., Wong, C.K., Yaus, K. and Qian, P.Y. (2001) Long Term Changes in Water Quality and Phytoplankton Characteristics in Port Shelter, Hong Kong from 1988-1998. Marine Pollution Bulletin, 42, 981-992.

[18] Nair, P.V.R., Joseph, K.J., Balachandran, V.K. and Pillai, V.K. (1975) A Study on the Primary Production in the Vembanad Lake. Bulletin of the Department of Marine Sciences, 7, 161-170.

[19] Ravindran, K., Appukuttan, K.K., Pillai, V.N.S., et al. (2006) Report of the Committee of Experts on Ecological and Environmental Impact of Dredging at Vaduthala Kayal and Vaikam Kayal, Kerala.

[20] Muduli, B.P. and Panda, C.R. (2010) Physico Chemical Properties of Water Collected from Dhamra Estuary. Indian Journal of Environmental Sciences, 1.

[21] Mansor, M.I., Mohammad-Zafrizal, M.Z., Nur-Fadhilah, M.A., Khairun, Y. and Wan-Maznah, W.O. (2012) Temporal and Spatial Variations in Fish Assemblage Structures in Relation to the Physicochemical Parameters of the Merbok Estuary, Kedah. Journal of Natural Sciences Research, 2, 112-127.

[22] Arnold, W.S., White, M.W., Norris, H.A. and Berigan, M.E. (2000) Hard Clam 
(Mercenaria spp.) Aquaculture in Florida, USA: Geographic Information System Applications to Lease Site Selection. Aquacultural Engineering, 23, 203-223.

[23] Buitrago, J., Rada, M., Hernández, H. and Buitrago, E. (2005) A Single-Use Site Selection Technique, Using GIS, for Aquaculture Planning: Choosing Locations for Mangrove Oyster Raft Culture in Margarita Island, Venezuela. Environmental Management, 35, 544-556. https://doi.org/10.1007/s00267-004-0087-9

[24] Pérez, O.M., Ross, L.G., Telfer, T.C. and Barquin, L.M.C. (2003b) Water Quality Requirements for Marine Fish Cage Site Selection in Tenerife (Canary Islands): Predictive Modeling and Analysis Using GIS. Aquaculture, 224, 51-68.

[25] Radiarta, I.N. and Saitoh, S. (2008) Satellite-Derived Measurements of Spatial and Temporal Chlorophyll-A Variability in Funka Bay, Southwestern Hokkaido, Japan. Estuarine, Coastal and Shelf Science, 79, 400-408.

[26] Paul, T.T. (2008) Mapping of Clam Beds in Vembanad Lake Using GIS and Remote Sensing. Dissertation, Central Institute of Fisheries Education.

Submit or recommend next manuscript to SCIRP and we will provide best service for you:

Accepting pre-submission inquiries through Email, Facebook, LinkedIn, Twitter, etc. A wide selection of journals (inclusive of 9 subjects, more than 200 journals)

Providing 24-hour high-quality service

User-friendly online submission system

Fair and swift peer-review system

Efficient typesetting and proofreading procedure

Display of the result of downloads and visits, as well as the number of cited articles

Maximum dissemination of your research work

Submit your manuscript at: http://papersubmission.scirp.org/

Or contact jgis@scirp.org 